\title{
Corpo perfeito ou imperfeito?
}

\author{
Perfect imperfect body?
}

\author{
${ }^{1}$ Claudiomiro Ramos Moreira; ${ }^{2}$ Marivane Borges \\ crmclaudiomoreiracrm@gmail.com ${ }^{1}$, Universidade Federal do Pampa; \\ marivaneborges01@gmail.com, Universidade Federal do Pampa².
}

\begin{abstract}
Resumo
O propósito deste texto é revelar, a construção social do corpo perfeito/imperfeito e as relações possíveis com a mídia. E contribuir para a compreensão sobre o corpo e a mídia na sociedade capitalista contemporânea, num campo de estudo controverso e complexo, impregnado de subjetividades e de conflitos. A análise foi procedida em referências bibliográficas e é fundamental para as condições concretas que permeiam as políticas sociais, as quais são marcadas pela história das tecnologias de normalização dos corpos e intervenção dos dispositivos biotecnológicos de produção da subjetividade, concernentes às questões de relações de gênero.
\end{abstract}

Palavras-chave: Corpo; Consumo; Perfeição; Imperfeição; Mídia.

\begin{abstract}
The purpose of this paper is to reveal the social construction of the perfect / imperfect body and possible relationships with the media. And contribute to the understanding of the body and the media in contemporary capitalist society, a controversial field of study and complex, imbued with subjectivity and conflict. The analysis was preceded in references and is critical to the concrete conditions that permeate social policies, which are marked by the history of technology standardization bodies and intervention of biotechnological devices production of subjectivity concerning issues of gender relations.
\end{abstract}

Key-words: Body; Consumption; Perfection; Imperfection; Media.

\section{Introdução}

O texto exprime reflexões geradas pelo estudo e análise procedida em referências bibliográficas. Enfatiza as inquietações sobre o consumo e a relação da perfeição/imperfeição do corpo. A procura da (possível) perfeição está relacionada intimamente ao sentimento de ser “aceito", ou seja, "estar e sentir-se pertencente a um grupo" que, por sua vez pode incluir e excluir. Em uma sociedade onde prevalecem as relações econômicas de caráter individualista e consumista, o corpo perfeito torna-se objeto de maior desejo. 
O enfoque maior recai sobre a questão da mídia, a qual é usada como ferramenta para disseminar e reforçar cotidianamente o conservadorismo, o padrão de beleza, e mexer com o imaginário de cada ser humano, contribuindo para a formação de identidades simbólicas.

Este texto está organizado em duas partes: Em uma primeira parte desenvolve uma reflexão histórica conceitual, sobre a relação do corpo e seus múltiplos significados em uma sociedade capitalista que privilegia o consumo do corpo, destacando os valores, as singularidades e a relação estabelecida corpo e sociedade por meio de interações. Em sua segunda parte o texto apresenta a influência da mídia na busca de um corpo perfeito, compreensão favorecida a partir do enquadre do primeiro tópico, em seu movimento de constituição como objeto de uso e consumo, no que se refere à complexidade dos significados sobre o corpo.

Em uma sociedade individualista, que possui como base de sustentação as relações econômicas, com privilégio para o "consumo", vemos surgir, dentre outros tantos objetos consumíveis, um que se sobressai entre os demais - o corpo. O corpo é inscrito nesta sociedade de consumo, como o objeto de maior apelo visual, é dado a ele os holofotes do "culto", desta forma, o que era antes escondido, agora deve ser mostrado em sua máxima forma.

O corpo torna-se sinal de aceitação social, assim ter uma visão um pouco mais clara sobre esse "novo" objeto de culto é mister para entender as subjetividades em construção, que permeiam as relações sociais. Logo este culto ao corpo deve ser visto como o culto ao uso e consumo do corpo. Mas o que vem a ser o "corpo" em questão?

\section{O corpo e seus múltiplos significados}

De forma não menos literal, e buscando o seu significado mais geral, "corpo" significa "tudo o que tem extensão e forma, e a estrutura física do homem (MICHAELIS, 2015)". Mas ao se fazer uma análise deste, percebe-se que o corpo é mais que uma simples estrutura física, que está sob o domínio exclusivo da biologia. Caso deixássemos o entendimento sobre o corpo apenas no âmbito biológico, veríamos o corpo como um sistema orgânico, constituído apenas de nervos, ossos, órgãos, etc., ou seja, algo que cumpre funções orgânicas.

Por outro lado, se adotada a visão religiosa sobre o corpo, ela o coloca em um lugar demasiado rebaixado, pois está o via (e ainda o vê) apenas como receptáculo da alma. “A alma caiu neste corpo que a escraviza (DAGOGNET, 2012, p. 10)". 
A visão do corpo como prisão da alma, pode ser encontrada na Grécia com Platão. Este por sua vez, apresenta em um de seus diálogos, o corpo como algo miserável, está visão negativa sobre o corpo, é apresentada em um dos diálogos de O Banquete, onde o médico Erixímaco "chama de mau o amante vulgar que ama mais o corpo que a alma" (PLATÃO apud DAGOGNET, 2012, p.12). O corpo é mostrado como sendo local de perdição, visto que Platão prega o "autodomínio", isto é, o domínio sobre o corpo e os seus desejos corporais. Logo, a visão de um corpo miserável acaba por influenciar a cidade (sociedade), assim há a ligação do corpo com o social. "Do corpo nascem e se propagam as significações que fundamentam a existência individual e coletiva; ele é o eixo da relação com o mundo, [...] (LÊ BRETON, 2007, p. 7)”. Vemos que a relação indivíduo e sociedade e dada através do uso do corpo, ele é o elo de ligação entre o individual e o social.

Esta relação com o mundo, dada através do uso do corpo, trás a este a dificuldade de afirmá-lo em sua plenitude, ou seja, mostrar o corpo em sua representação máxima. Esta dificuldade decorre dada à sua complexidade, ou seja, o corpo é local de simbolismos singulares e plurais, objeto cultural e social, impregnado de sentido e valores que decorrem do tempo histórico e social ao qual se faz presente. Ainda se pode dizer que é a partir e por meio do corpo, que o sujeito constrói sua relação com o mundo, o corpo e moldado pelas relações existentes entre o indivíduo e sociedade. O que pode ser observado é que todas as relações sejam elas privadas ou públicas, se dão através do corpo, são tecidas pelo uso do corpo.

$\mathrm{O}$ que nos remete, a um dos grandes problemas em relação ao dizer ou buscar a afirmar o que é o corpo, ela é dada, por meio de nossa consciência, ou seja, como vemos nosso corpo. Sartre (2011) assevera em seu livro "O Ser e o Nada", que a visão/descrição do meu corpo (órgãos, sistema nervoso e dentre outras constituições que o formam) não é tal qual é para mim, ou seja, para eu ter uma visão mais clara de meu corpo, eu tenho que unir minha consciência, não ao meu corpo, mas ao de outros. Mas ao se fazer isso, vejo meu corpo como meio do mundo, isto é, existe o "eu" vendo o meu corpo. ${ }^{1} \mathrm{O}$ que ocorre e a incapacidade de ver o corpo em si. O corpo é o meu ser, eu estou nele, mas visto que quando tenho que explicá-lo, utilizo o corpo de outro, dado a incapacidade de ver o meu cérebro, por exemplo, ${ }^{2}$ de forma mais sucinta, "o corpo me oferece um ponto de vista do mundo, mas em contrapartida não temos nenhum ponto de vista sobre ele (DAGOGNET, 2012, p. 5)”.

\footnotetext{
${ }^{1}$ Sartre se utiliza do exemplo de ver a si mesmo durante uma radioscopia, no qual o autor diz que está do lado de fora, no meio do mundo, ou seja, não há possibilidade de se ver vendo (2011, p. 385-386).

${ }^{2} \mathrm{O}$ exemplo aqui citado tem como base a frase "Não vi e jamais verei meu cérebro, ou minhas glândulas endócrinas". Expressão retirada do livro O Ser e o Nada de Jean-Paul Sartre (2011).
} 
Por que há necessidade de busca do "eu" no corpo? Pois como dito antes o corpo se inscreve como, significação de sua "existência individual e coletiva (LÊ BRETON, 2007, p. 7)", ou seja, a visão do eu constituído no corpo, trás ao corpo a característica individual, eu sou meu corpo, e através dele exerço minha individualidade, e me faço ser individual no convívio social. Desta forma há a busca para se reconhecer individual aos demais corpos, o que se busca é reconhecer o "eu” presente neste corpo.

É esta representação do "eu", que leva a necessidade de uma imagem singular de nosso corpo neste caso o "eu" singular que deve possuir um significado próprio, que tem como meta a distinção entre dos demais corpos que habitam a sociedade. As modificações corporais (tatuagens, piercings, cirurgias plásticas, sessões de musculação), visam dar ao corpo, uma identidade própria "singular", o objeto corpo por meio destas mudanças, ganha um significado diferenciado dos demais corpos.

É esta singularidade que nós trás um paradoxo existente no corpo, que diz respeito a sua singularidade, isto é, o seu próprio significado, pois o corpo é local de significados variados, nas palavras de Lê Breton (2007) “o corpo é uma estrutura simbólica, local possível de unir variadas formas de culturas". O paradoxo aqui exemplificado se encontra exatamente nas variadas formas de culturas, que unidas no corpo, formam a sua singularidade única perante os demais corpos encontrados na sociedade.

A singularidade do corpo faz com que este tenha formas diferenciadas de expressão. Assim adentramos no campo referente às técnicas do corpo. As técnicas do corpo são dadas através do que chamamos ações do corpo, tais como, "gestos, a própria ação do corpo, sincronias musculares" (Lê Breton, 2007, p.38). Estes "gestos" corporais, nas palavras de Mauss apud Lê Breton (2007), modificam-se com o passar de geração em geração. Os gestos são mudados, pois, não se encontram no mesmo período histórico e social, em referência a geração anterior. Mauss apud Lê Breton (2007, p. 39), ainda nos diz que "O corpo é o primeiro e o mais natural instrumento do homem. Modelado conforme os hábitos culturais, ele produz eficácias práticas". Isto mostra que o corpo é mais que uma forma constituída de carne, ele é constituído de gestos, ações desenvolvidas pela carne que age. E estes gestos possuem significados diferenciados, que dependem da sociedade e tempo no qual se encontram. Tais gestos tendem a mudar entre grupos que, na sua maioria são diferentes entre si.

Gordon Hewes apud Lê Breton (2007, p. 41) estuda os gestos corporais, que tangem formas das "técnicas corporais como estar sentado ou manter-se em pé". Neste estudo o autor aponta que tais técnicas, são desenvolvidas no âmbito, da relação entre o fisiológico e 
anatômico e também cultural. As técnicas corporais são uma parte constitutiva do corpo, estas técnicas apreendidas, são uma forma de adaptação do corpo ao seu meio. "Nessa educação, a parte do mimetismo tem uma influência que não pode ser negligenciada" (LÊE BRETON, 2007, p. 43). De tal modo, as técnicas demonstram a capacidade de adaptação do corpo, visto de forma mais saliente, quando desempenhamos uma atividade até então inédita a nós, mas acabamos por apreender a desempenhá-las através da reprodução de tais gestos.

Dentre as constituições do corpo temos ainda a gestualidade. "A gestualidade referese às ações do corpo quando os atores se encontram; ritual de saudação ou de despedida (sinal de mão, aceno de cabeça, aperto de mão, abraços, beijos no rosto, [...])" (LÊ BRETON, 2007, p. 44). Em um estudo sobre a gestualidade Davis Efron apud LÊ BRETON (2007, p. 44) constata que a forma de usar o corpo é estabelecida sobre três coordenadas são elas:

\footnotetext{
a dimensão espaço-temporal (amplitude dos gestos, forma, plano de desenvolvimento, membros utilizados, ritmo), a dimensão interativa (tipo de interação com o interlocutor, com o espaço ou com os objetos que fazem parte dele) e a dimensão lingüística (gestos cuja significação é independente dos propósitos tidos ou ao contrário que os desdobra) ( EFRON apud LÊ BRETON, 2007, p. 44,).
}

A conclusão que Efron apud Lê Breton (2007) chega, é que, a gestualidade do corpo sofre uma forte influencia do social, neste caso o corpo não encontra-se iseto de infuencias exteriores. O referido estudo quebra a visão que cada indivíduo age conforme sua "raça", ou seja, que determinado indivíduo age conforme a hereditariedade da raça a qual pertence. Assim a gestualidade corporal e um fato social e cultural, não uma força da natureza que se impõem sobre os indivíduos (LÊ BRETON, 2007).

A relação estabelecida corpo/sociedade é dada através de interações. Esta interação para não se tornar caótica utiliza-se de códigos de conduta, a isso damos o nome de etiqueta corporal Lê Breton (2007). A etiqueta corporal é utilizada para o controle da imagem apresentada ao outro, este código é adotado de forma espontânea em função das normas que guiam o agir no social. Mesmo sendo quase que imperceptíveis, as interações possuem suas regras, a etiqueta corporal e suas regras visam exatamente minimizar qualquer infração que possa ocorrer nesta interação entre os atores (homem). Pode-se tomar a "etiqueta corporal" como um conjunto de normas que, seguidas impedem a pessoa de cair na confução no uso de sua gestualidade, ação e nas tecnicas corporais (como a forma de sentar-se). O aprendizado da etiqueta corporal independe de ensino formal, como as variadas formas do corpo de expressar, elas são aprendidas no decorrer do tempo - elas são social e cultural -, é a forma do corpo se adaptar ao ambiente. 
O que é notado de forma elementar é essa coação social sofrida pelo corpo, pode-se ainda dizer, que o peso social e cultural sobre o corpo, por algumas vezes supera o natural. Isso é visto nas mudanças drásticas sofridas e impostas ao corpo, como as plásticas com fins estéticos - mudanças faciais e corporais -, isto é, o corpo social superando o corpo natural ${ }^{3}$.

Desta forma o corpo deve ser visto como algo muito mais que, uma forma física constituída de carne, deve-se ver além de sua forma física -magro, gordo, sarado, definido, musculoso-, corpo é agente social, que esta além da simples forma física, hoje, tão cultuada como a única e derradeira forma de ver o corpo.

\section{A influência da mídia na busca de um corpo perfeito/imperfeito}

A mídia e os meios de comunicação são ferramentas, nas quais o capitalismo se utiliza para estimular o consumo e ditar moda. Atualmente, a influência dela na sociedade é devastadora e massificadora, onde os estereótipos midiáticos são disseminadores de identidades simbólicas, costumes, modas dentre outras manifestações.

O objeto de trabalho midiático sustenta-se, na construção de uma identidade simbólica, e para materialização da mesma, utiliza-se de instrumentos como a persuasão, para que desta forma possa ter mais audiência, repercussão entre outros, e com isso vender um produto. Com efeito, as relações sociais constroem-se permeadas pelos meios de comunicação, que são eles: a televisão, a internet, as propagandas publicitárias entre outros. Atualmente, existe um forte apelo midiático ${ }^{4}$ do ser mulher e do ser homem, com características pré-concebidas nesse imaginário simbólico, tais como: tem que ser alta magra, cintura de violão, e o homem tem que ser alto, sarado, musculoso, ou seja, ter boa aparência etc. Uma idealização de ser musas(os) de beleza feminina e masculina, que é produzido e reproduzido pela mídia neste século XXI está muito distante da inocência e ingenuidade como era visto em décadas recente, o que demonstra, sobretudo, a voracidade do sistema capitalista sobre as relações sociais e, os avanços biotecnológicos nas últimas décadas.

Deste modo, o padrão de beleza é uma forma seletiva e individualista, onde o corpo virou objeto de desejo e mercadoria. E a mídia torna-se instrumento de manipulação do imaginário tanto de homens como de mulheres, podendo obter a exploração máxima de todas as possibilidades simbólicas da imagem, como a criação de curvas bem mais sensuais, lábios carnudos e desejosos e seios proeminentes.

\footnotetext{
3 Utiliza-se o termo corpo natural, para designar o corpo que não sofreu nenhuma mudança estética, contrapondo com os fins estéticos (cirurgias plásticas).

${ }^{4}$ Observamos que existe, não só o apelo midiático na construção dos corpos, mas também, fortemente a indústria médica, a qual não é objeto de discussão neste texto. Embora, as/os autoras/es problematizam esta discussão no espaço acadêmico.
} 
Ao mesmo tempo, destacam-se, também, as relações de gênero que, se refere às relações sociais desiguais de poder entre homens e mulheres e, que é a expressão de uma construção social do papel do homem e da mulher a partir não somente das diferenças sexuais e de classes sociais, mas de todas as relações que permeiam o cotidiano. Em outras palavras, as relações de gênero são produto de um processo pedagógico que se inicia no nascimento e que é constituída pelas mais diversas instâncias da sociedade, tais como: a instituição familiar, a instituição escolar, a sociedade, a mídia, etc. Reforçando a desigualdade existente entre homens e mulheres, ou mulheres e mulheres ou homens e homens, principalmente em torno de quatro eixos: a sexualidade, a reprodução, a divisão sexual do trabalho e o âmbito público/privado e cidadania.

Dentro do conteúdo de "matriz excludente pela qual os sujeitos são formados" que lança seres abjetos, aqueles que ainda não são sujeitos Butler (2003). Como essas práticas produzem práticas reguladoras de formação e divisão de gênero constituem a "[...] identidade, a coerência interna do sujeito, e, a rigor, o status auto-idêntico de pessoa [...]" (Butler, 2003, p. 38), estas não são características da condição de pessoa, mas normas de inteligibilidade:

\begin{abstract}
Em outras palavras, a "coerência" e a "continuidade" da "pessoa" não são características lógicas ou analíticas da condição de pessoa, mas, ao contrário, normas de inteligibilidade socialmente construídas e mantidas. Em sendo a "identidade" assegurada por conceitos estabilizadores de sexo, gênero e sexualidade, a própria noção de "pessoa" se veria questionada pela emergência cultural daqueles seres cujo gênero é "incoerente" ou "descontínuo", os quais parecem ser pessoas, mas não se conformam às normas de gênero da inteligibilidade, pelas quais as pessoas são definidas (BUTLER, 2003, p. 38).
\end{abstract}

Nessa linha de raciocínio, os meios de comunicação disponibilizam ferramentas para a construção das normas de inteligibilidade, como a erotização para homens e mulheres, como também, nesta relação social e midiática se constitui uma questão de opressor e oprimido, porque são duas classes claramente distintas, uma que tem o acesso ao produto (moda e beleza) e a classe que não o tem e, com isso sofre discriminação e rotulação por não estar no padrão de beleza que a mídia propaga.

Demais, falar do corpo perfeito e imperfeito é um desafio, pois fazer crítica a mídia como produtora de mercados dos corpos, em específico, é uma área nebulosa, complexa e dinâmica, dado o seu caráter contraditório, no modo de produção, o qual vivenciamos, ou seja, o modo de produção capitalista. A indagação que se faz é: como fazer os enfrentamentos e com isso construir um conhecimento coletivo e politizado? Criticar a mídia ou usar a mídia a favor? Com tais indagações, reflete-se que lutas e resistências devem ser travadas 
cotidianamente, e que também, não podemos transformar a mídia como algo exclusivamente alienante, e sim também um campo fértil, como ferramenta de combate as opressões.

Para adensar a discussão nos reportamaos a Saffioti (2001) para esclarecer que o contexto social estabelece uma relação de poder entre homem e mulher ao dizer que:

O outro ângulo a partir do qual se podem analisar as relações entre homens e mulheres é o individual. Casais são capazes, embora raramente, de construir uma relação par, igualitária, sem hierarquia. Isto ocorre raramente, uma vez que está convivência democrática entre homens e mulheres contraria todo o contexto social no qual acontece (SAFFIOTI, 2001, p.123).

O que Saffioti (2001) está querendo dizer, é que as relações de poder estão postas na sociedade e as instituições todos os dias afirmam isso, principalmente, a mídia que reproduz esta visão mais conservadora.

Quando falamos de aceitação do corpo é mais uma estratégia do sistema capitalista para vender seu nicho e assim dizer que estão incluindo, mas na verdade isso é só aparência disfarçada, um exemplo claro do que estamos falando são as modelos plus size, onde o sistema capitalista mercadológico viu uma oportunidade, e desta forma muitas pessoas pensam que estão sendo inclusas, mas na verdade isso é um ledo engano, pois esta é uma aceitação imposta pela sociedade, acabamos não percebendo a exclusão que a própria sociedade capitalista faz reiteradamente, na qual o corpo está sendo exposto como uma mera mercadoria na vitrine, neste mercado que explora tanto homens quanto mulheres.

Portanto, o consumo segundo Bauman (2008, p.107) é “[ [... em primeiro lugar, a preocupação de 'estar e permanecer á frente' (á frente da tendência de estilo - ou seja, no grupo de referência dos 'pares', 'dos outros que contam' e cuja aprovação ou rejeição traça uma linha entre o sucesso e o fracasso)".

Ou nas palavras de Michel Maffesoli apud Bauman (2008),

[...] sou o que sou porque o outro me reconhece com tal", enquanto "a vida social empírica não é senão uma expressão de sentimento de pertencer de pertenças sucessivas - Alternativa sendo um sucesso de rejeição ou de uma exclusão afinal como penaliza pelo fracasso em abrir caminho para o reconhecimento [.....]( BAUMAN,2008, p. 107) .

Com isso, Bauman (2008) quer dizer que o consumo é algo inerente e imovível do ser humano, onde pode estar ligado no sentido do "estar e pertencer" a um grupo e cuja sua aprovação e rejeição está ligada a um tipo de produto e serviço, ou seja, que compramos algo muitas vezes para conseguir um reconhecimento ou pertencimento por possuir determinado tipo de produto. 
O que é perceptível neste processo de consumo e de perfeição (seja a moda, beleza, entre outros), é que precisamos voltar historicamente, ou seja, fazer o movimento de "tour" para compreender os meios de produção do capitalismo a qual se utilizam de várias ferramentas para persuadir o indivíduo e com isso procura mostrar o que é belo e o que mexe com o imaginário de todas as pessoas, fortalecendo as relações sociais de dominante e dominado.

Também destaca-se que o ser humano sempre está e estará em busca da perfeição, no entanto, ele não esta totalmente satisfeito consigo, seja qual aspecto for de vida social, estético, econômico e etc. E a constante procura da perfeição faz com que cada vez mais, a mídia explore paulatinamente esse mercado onde se preocupa mais com aparência do que com a essência ocasionando assim sujeitos mais infelizes.

Para finalizar, nas palavras de Foucault (2014), o domínio dos corpos direcionados ao consumo propicia a produção de corpos masculinos e femininos em antagonismo, a subalternização dos sujeitos do feminino e as desigualdades baseadas na diferença anatômica do sexo que tornam invisíveis as "sexualidades disparatadas" 5 ".

\section{Considerações finais}

A relação existente entre mídia/corpo é íntima, é uma relação que deve ser vista como comercial, onde se vende um objeto (o corpo) a um possível comprador. Esta relação comercial não faz distinção de classe social, pois seu intuito é de vender, ou seja, o importante é vender e o consumir. Mas ao se afirmar que não faz distinção de classe social, se deve notar, que não quer dizer que não há relação de poder (a padronização do corpo e mais forte no corpo feminino), consumindo você é igual aos demais consumidores, o ato de consumir, torna-se isento de distinção e preconceito, basta consumir (apesar de que este ato benevolente de não preconceito nem sempre ocorra).

Se o ato de consumir é a isenção de distinção entre os consumidores, o ato de não consumir não é assim. Não consumir, é exatamente o inverso, o que se tem é a exclusão social, pelo fato de você, não estar em um padrão (de consumo, corporal e etc.). O que se tem são homens e mulheres tornando-se objeto, neste caso seus corpos tornam-se objetos consumíveis, mas ao mesmo tempo devem consumir um padrão de corpo (sarado, malhado, esculpido nas academias ou em cirurgias).

Transformar o corpo em objeto, e depois vende-lo é o primeiro passo para construir uma sociedade de consumo de "corpos". Mas vende-lo não basta, deve-se ter um padrão de

\footnotetext{
5 "Disparatadas": a origem do termo é o francês disparate, usado por Michael Foucault (2014), o qual, por sua vez, designa contra senso, extravagância, ação ilógica ou estúpida.
} 
corpo para vender, assim define-se um corpo objeto no qual se coloca o termo "perfeito", ou seja, se você não se encaixa em tal padrão, seu corpo não é perfeito, logo você deve buscar entrar neste padrão, caso contrário à pessoa sofre o isolamento social, pois o corpo é o vínculo entre o individual e o social.

Desta forma, o estar fora da moda do corpo padronizado, é estar fora do social, e isso se deve ao fato de você não se adequar a sociedade, veja, o problema é "você" e não o social (que se utilizando da mídia) induz/produz um corpo padrão que muitas vezes não condiz com a constituição do indivíduo. Mas neste caso, existem os meios para alcançar o "corpo perfeito" às cirurgias plásticas (que aumentam todo ano). Transformar o seu corpo em algo feio, fora da moda, imperfeito, visa unicamente, fazer o indivíduo sentir-se desconfortável em seu próprio corpo, assim você irá buscar o corpo no qual seja feliz e sinta-se satisfeito e seja finalmente aceito socialmente.

Assim poderia se dizer que, alcançado o corpo almejado não haveria mais nada para mudar no corpo, já que agora ele respeita os padrões sociais? Seria o certo dentro desse padrão estabelecido, mas isso não ocorre. Com o intuito de vender e lucrar com o corpo, a moda/mercado junto com as mídias, modificam o "corpo", se ontem, o corpo perfeito era o definido e musculoso, hoje e o magro com viés mais natural. Essas mudanças corporais visam tirar a durabilidade de um tipo uníco de corpo aceitável. Pois como diz Bauman (2008, p. 64). "A sociedade de consumo prospera enquanto consegue tornar perpétua a não-satisfação de seus membros $[\ldots]]^{\prime}$..

O jogo coercitivo exercido pela mídia sobre o corpo torna-o objeto isento de significados, ou seja, o único significado que o corpo possui é o aceito e o não aceito, perfeito/imperfeito. O que ocorre é a separação sujeito e corpo, seu corpo "natural", ou seja, aquele sem modificações corporais, já não o representa, pois ele não é aceito pela sociedade. Desta forma busca-se aceitação social através das mudanças corporais, eu recorro a mudança para ser aceito, e não busco a mudança social para ser aceito com o meu corpo.

O que se vê realmente e a separação do "eu" e meu corpo, e finalmente a perda de seus significados particulares, já que deve ser o corpo padronizado, igual ao demais corpos que estão em sociedade. O que se deve buscar é a volta do corpo enquanto corpo ligação do individual e social, em igual relação.

Neste sentido, reforçamos que o principal objetivo deste artigo, que não se esgota aqui, é denunciar, por meio de teorias e de políticas, o uso e consumo dos corpos, não só pela mídia, mas pela sociedade de modo geral. Assim, buscamos contribuir, sobretudo, com elementos que auxiliem na transformação da maneira de pensar, de aprender, de conhecer e de 
estar no mundo, tornando estes processos mais cônscios, principalmente do direito ao corpo sem coerção do mercado.

Por fim, enfatizamos que, as políticas sociais são marcadas pela história das tecnologias de normalização dos corpos e intervenção dos dispositivos biotecnológicos de produção da subjetividade, concernentes às questões de relações de gênero e sexualidade. Também, a maneira como se formulam, implementam e executam políticas sociais, e o corpo é uma das dimensões fundamentais da vida e da sociabilidade, e tem consequências públicas e privadas. Uma sociedade que faz interpelações que atribuem às normas de inteligibilidade, deixam somente o espaço de consumo do corpo perfeito/imperfeito das demais orientações, e não o reconhecimento de várias possibilidades de vivência.

\section{Referências}

BAUMAN, Zygmunt. Vida para consumo: a transformação das pessoas em mercadoria. tradução Carlos Alberto Medeiros. - Rio de Janeiro: Jorge Zahar Ed., 2008

BUTLER, Judith. Problemas de Genêro:Feminismo e Subversão da Identidade. Rio de Janeiro: Civilização Brasileira, 2003.

DAGOGNET, François. O corpo. Tradução de Michel Jean Maurice Vincint. - Rio de janeiro, RJ: Forense Universitaria Ed., 2012.

LÊ BRETON, David. A sociologia do corpo. $2^{\mathrm{a}}$. Ed. Tradução de Sonia M. S. Fuhrmann Petrópolis, RJ: Vozes, 2007.

FOUCAULT, Michel. História da Sexualidade - A vontade de saber. São Paulo: Editora Paz e Terra, 2014.

MICHAELIS. Dicionário Online. Disponível em http://michaelis.uol.com.br/. Acesso em 20 de abril de 2015.

SAFFIOTI, Heleieth I. Contribuições feministas para o estudo da violência de gênero. In: cadernos pagu (16) 2001.

SARTRE, Jean-Paul. O ser e o nada: Ensaio de ontologia fenomenológica. Tradução de Paulo Perdigão. 20ª . Ed. Petrópolis RJ: Vozes, 2011. 